\title{
Mudanças na legislação farmacêutica durante a pandemia de Covid-19
}

\author{
Changes in pharmaceutical legislation during Covid-19 pandemic \\ Cambios en la legislación farmacéutica durante la pandemia Covid-19
}

Expedito Junio da Silva Sousa

ORCID: https://orcid.org/0000-0003-3220-1459

Centro Universitário Maurício de Nassau, Brasil E-mail: juniorsous88@hotmail.com

Nilson de Jesus Pereira Gonçalves ORCID: https://orcid.org/0000-0001-5470-6197 Centro Universitário Maurício de Nassau, Brasil

E-mail: niylsongoncalves@hotmail.com

Andressa Almeida Santana Dias ORCID: https://orcid.org/0000-0002-1671-8338 Centro Universitário Maurício de Nassau, Brasil E-mail: aasadias@gmail.com

Maria Cristiane Aranha Brito ORCID: https://orcid.org/0000-0002-6979-8773 Centro Universitário Maurício de Nassau, Brasil E-mail: tiane91@ hotmail.com

Ana Paula Muniz Serejo ORCID: https://orcid.org/0000-0002-4376-4364 Universidade Federal do Maranhão, Brasil E-mail: apsmuniz1@gmail.com

Maurício Avelar Fernandes ORCID: https://orcid.org/0000-0002-0795-2085 Centro Universitário Maurício de Nassau, Brasil

E-mail: mauricioa.fernandes@ hotmail.com

\begin{abstract}
Resumo
A infecção pelo SARS-CoV-2 iniciou-se em dezembro de 2019 na região de Wuhan, na China, e propagou-se pelo mundo em 2020. O Coronavírus pertence à família Coronaviridae e promove uma doença respiratória chamada de Covid-19. A raça humana foi intensamente prejudicada perante a uma pandemia atípica e de acelerado crescimento, surprendendo toda sociedade, principamente os profissionais da área de saúde, no combate dessa doença devastadora, sendo fundamental repensar nos preceitos morais da humanidade como por exemplo consciência social. $\mathrm{O}$ estudo trata-se de uma revisão narrativa que tem por objetivo geral descrever as mudanças que ocorreram na legislação farmacêutica em meio a pandemia da Covid-19. Tem-se por objetivos específicos descrever como eram as normas antes da pandemia se instaurar, descrever as mudanças que ocorreram e conhecer quais as implicações para o farmacêutico em sua atuação. Com a pandemia do Coronavírus, houve muitas alterações nas legislações no intuito de diminuir a propagação viral através da diminuição do contato social e em relação ao tratamento farmacológico, modificando as prescrições e atualizando as listas de medicamentos controlados. Dessa maneira percebe-se a importância do profissional farmacêutico relacionado ao controle da disseminação do vírus e do cuidado aos pacientes portadores da doença.
\end{abstract}

Palavras-chave: Legislação farmacêutica; Covid-19; Pandemia.

\begin{abstract}
The SARS-CoV-2 infection started in December 2019 in Wuhan province, China, and spreads worldwide in 2020. Coronavirus belongs to the Coronaviridae family and causes a respiratory disease called Covid-19. The entire humanity was strongly impacted in the face of an unexpected and rapidly expanding pandemic to Covid-19 that surprised everyone, especially health professionals, in coping with this overwhelming illness, making it necessary to consider moral norms to be observed, such as the sense of responsibility. The study is a narrative review whose general objective is to describe the changes that occurred in pharmaceutical legislation during the Covid-19 pandemic. The specific objectives are to describe what the rules were like before the pandemic was established, describe the changes that occurred and learn about the implications for the pharmacist in his performance. With the Coronavirus pandemic, there were many changes in legislation to reduce viral spread by decreasing social contact and in relation to pharmacological treatment, modifying prescriptions and updating the lists of controlled drugs. In this way, the importance of the pharmaceutical professional is perceived in terms of controlling the spread of the virus and caring for patients with the disease.
\end{abstract}

Keywords: Pharmaceutical legislation; Covid-19; Pandemic. 


\begin{abstract}
Resumen
La infección por SARS-CoV-2 comenzó en diciembre de 2019 en la provincia de Wuhan, China, y se propaga por todo el mundo en 2020. El coronavirus pertenece a la familia Coronaviridae y causa una enfermedad respiratoria llamada Covid-19. Toda la humanidad se vio fuertemente impactada ante una pandemia inesperada y una rápida expansión al Covid-19 que sorprendió a todos, especialmente a los profesionales de la salud, al hacer frente a esta abrumadora enfermedad, y es necesario considerar que se deben observar normas morales, como el sentido de la responsabilidad. El estudio es una revisión narrativa que tiene como objetivo describir los cambios que se produjeron en la legislación farmacéutica en la pandemia de covid-19. Los objetivos específicos son describir cuáles eran las normas antes de que se estableciera la pandemia, describir los cambios que se produjeron y conocer las implicaciones para el farmacéutico en su desempeño. Con la pandemia del coronavirus, ha habido muchos cambios en la legislación para reducir la propagación viral a través de la disminución del contacto social y en relación con el tratamiento farmacológico, modificando las prescripciones y actualizando las listas de medicamentos controlados. Así, se percibe la importancia del profesional farmacéutico relacionada con el control de la propagación del virus y la atención a los pacientes con la enfermedad.
\end{abstract}

Palabras clave: Legislación farmacéutica; Covid-19; Pandemia.

\title{
1. Introdução
}

A infecção pelo SARS-CoV-2 iniciou-se em dezembro de 2019 na região de Wuhan, na China, e alastrou-se pelo mundo em 2020. O Coronavírus pertence à família Coronaviridae e provoca uma patologia respiratória chamada de Covid-19. Em 30 de janeiro de 2020, a Organização Mundial de Saúde declarou que o surto do Coronavírus constituía Emergência de Saúde Pública de Importância Internacional (ESPII) e, em 11 de março de 2020, foi decretada a pandemia (Karuppiah, 2020).

No entanto, a pandemia de Covid-19 não é a primeira que a humanidade enfrenta ao longo de sua história. Contudo, ocorre em um momento em que o mundo está em crise ambiental, humanitária, econômica e de produção, em razão das guerras e dos seus refugiados. No contexto da América Latina, depois de uma década de desenvolvimento econômico e social observase, a partir de 2015, aumento da pobreza, piora dos indicadores do mercado de trabalho e estacionamento da redução da desigualdade de renda. No Brasil, soma-se a esse panorama, 13 milhões de pessoas vivendo em favelas, as dificuldades com saneamento básico e o aumento do emprego informal (Araujo et al., 2020).

Nesse cenário e levando em consideração ainda o forte impacto da pandemia nos serviços públicos e privados de saúde, fornecer tratamento eficaz e eficiente para pacientes com sintomas de Covid-19 tem sido um papel fundamental para os profissionais de saúde e equipes especializadas (Javeloth et al., 2020).

Com a pandemia, diversas mudanças regulatórias estão ocorrendo, afetando a dispensação de medicamentos, o funcionamento das farmácias e os serviços farmacêuticos. A medida foi motivada devido a emergência de saúde pública internacional provocada pela Covid-19, tendo como objetivo evitar visitas frequentes dos pacientes as unidades dispensadoras de medicamentos, como drogarias, farmácias e serviços de saúde relacionados, bem como reduzir o contato social que propicia a propagação do vírus (Araujo et al., 2020).

Diante dessa situação, e levando-se em conta as desigualdades socioeconômicas do atual contexto, evidencia-se a necessidade de implementação e consolidação dos sistemas de saúde universais, públicos e gratuitos que garantam às populações assistência à saúde, ações de prevenção a riscos e danos e de vigilância à saúde (Araujo et al., 2020).

Cabe ressaltar que, nos últimos anos, os sistemas de saúde públicos e universais vinham sendo atacados, e seus recursos financeiros retirados, em nome da austeridade neoliberal. Diante da pandemia, essa lógica revela-se falha e nota-se a importância do Estado como o principal indutor de políticas de saúde e de seguridade social que protejam a população (Javeloth et al., 2020).

Ante o exposto surge o seguinte questionamento: quais as mudanças ocorreram na legislação farmacêutica no Brasil em meio a pandemia de Covid-19 e quais as implicações para os farmacêuticos?

O estudo justifica-se, pois, diante desse cenário, é necessário que se tenha conhecimento das principais mudanças em 
meio a pandemia em relação as medicações e a atuação do farmacêutico para assim gerar subsídios para o profissional, sendo relevante pois contribui ao mesmo tempo para a realização do cuidado seguro, bem como para a fiscalização das condições de saúde e segurança no trabalho.

O estudo trata-se de uma revisão narrativa que tem por objetivo geral descrever as mudanças que ocorreram na legislação farmacêutica em meio a pandemia de Covid-19. Tem-se por objetivos específicos descrever como eram as normas antes da pandemia se instaurar; descrever as mudanças que ocorreram; e conhecer quais as implicações para o farmacêutico em sua atuação.

\section{Os Sérios Riscos da Doença e o Acometimento de uma Pandemia}

A pandemia de Covid-19 afetou seriamente nossa vida diária. Descrita pela primeira vez em Wuhan na China, no final de dezembro de 2019, a doença se espalhou pelo mundo todo. As taxas de mortalidade têm sido chocantes, com novos focos emergentes diariamente. Não foi relatado nenhum tratamento bem-sucedido. Não existia uma vacina para prevenir a propagação do vírus SARS-CoV-2, responsável pelo Covid-19 (Mahmood et al., 2020).

A reação em cadeia da polimerase com transcrição reversa em tempo real (rRT-PCR) é considerada a metodologia "padrão ouro" para o diagnóstico da infeção por SARS-CoV-2, embora também tenha suas limitações. Por conta da sua realização em tempo real, algumas etapas da PCR ocorrem simultaneamente, no mesmo tubo. Dessa maneira, as manipulações pós-amplificação são eliminadas do processo, diminuindo a possibilidade de contaminação e reduzindo a poucas horas a reação completa (Morales, 2020).

A raça humana foi intensamente prejudicada perante a uma pandemia atípica e de acelerado crescimento, surprendendo toda sociedade, principamente os profissionais da área de saúde, no combate dessa doença devastadora, sendo fundamental repensar nos preceitos morais da humanidade como por exemplo consciência social (Dourado, 2020).

\subsection{Responsabilidade social do farmacêutico}

Com relação a responsabilidade social do farmacêutico, que já era ampla e diversificada, agora passa a ter imenso significado no que diz a respeito ao controle e organização em farmácias, drogarias, análises laboratoriais e clínicas, além de outras responsabilidades (Javeloth et al., 2020).

A Diretoria de Assistência Farmacêutica da Secretaria de Saúde (DIASF) publicou uma nota normativa SEI/GDF 37693139 em 2020, com orientações sobre a disponibilidade e liberação de medicamentos durante o enfrentamento ao Coronavírus. Com isso, foi reorganizado o processo de trabalho para reduzir a circulação de pessoas e a sobrecarga dos serviços de saúde (Agência de Brasília, 2020).

Entre as mudanças está a extensão do prazo de validade de receitas médicas. Aquelas de medicamentos padronizados para atenção básica e média complexidade, de uso prolongado, crônico ou contínuo, com prazo de validade máxima de 180 dias passarão a valer até 240 dias a partir da data de emissão, regulamentado pela nota técnica $\mathrm{n}^{\circ}$ 134/2020CPFP/CGAFB/DAF/SCTIE/MS.

Além disso, a nota técnica $\mathrm{n}^{\circ} 134 / 2020$ afirma que no caso de medicamentos padronizados do componente especializado, as autorizações de procedimentos ambulatoriais (APAC) que terminem entre fevereiro e maio deste ano serão renovadas automaticamente, por período adicional de três meses, em caráter excepcional, sem necessidade de apresentação de nova LME - Laudo de Medicamento Especializado e prescrição médica, desde que não haja mudança na dose, quantidade dispensada e/ou medicamento Prescrito (Agência de Brasília, 2020).

A liberação também passou por mudanças, através da RDC n 357, de 24 de março de 2020, os medicamentos 
poderão ser entregues de acordo com seus estoques, para 60, 90 e até 120 dias, sempre levando em consideração a disponibilidade de estoque atual, para garantir o acesso de todos os usuários e diminuir a circulação provocada pelos retornos às farmácias (Silva, 2020).

\section{Metodologia}

O presente trabalho é um estudo descritivo, a partir de uma revisão narrativa, onde foram utilizados estudos e documentos regulamentadores publicados no período de 2009 a 2020, na qual utilizou- se de bases de dados como fonte para a pesquisa bibliográfica, nos possibilitando um aperfeiçoamento e amadurecimento de ideias referentes às mudanças de legislação que envolvessem diretamente o profissional farmacêutico atuando no âmbito de farmácias e drogarias. Esse tipo de estudo não utiliza critérios explícitos e sistemáticos para a busca e análise crítica da literatura. A busca pelos estudos não precisa esgotar as fontes de informações. Não aplica estratégias de busca sofisticadas e exaustivas. A seleção dos estudos e a interpretação das informações podem estar sujeitas à subjetividade dos autores (Ferenhof \& Fernandes, 2016). O estudo realizado nas bases de dados virtuais presentes no Portal de LILACS: Literatura Latino-Americana e do Caribe em Ciências da Saúde, Scielo - Scientific Electronic Library Online e Medical Literature Analysis and Retrieval System Online (MEDLINE).

Figura 1: Caracterização do percurso da busca de dados. São Luís, 2020.

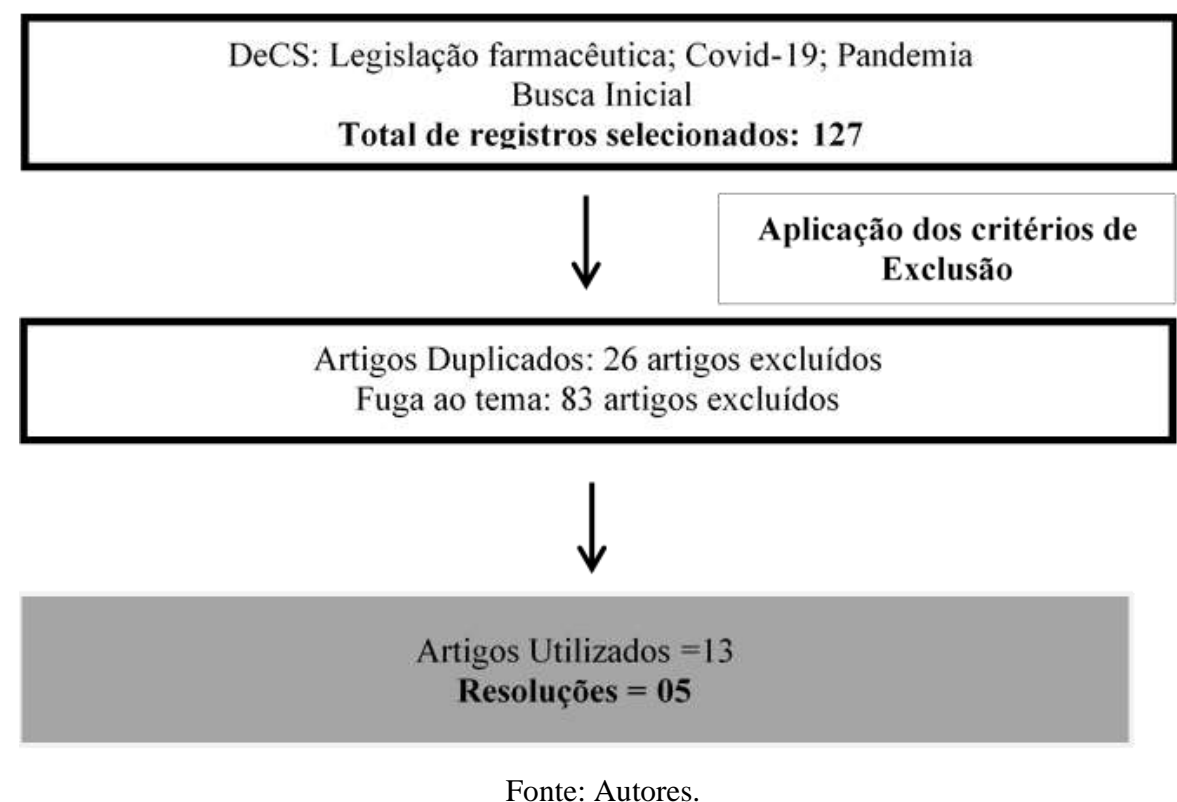

\section{Resultados e Discussão}

Diante do que foi apresentado, faz-se necessário apresentar as principais mudanças no âmbito farmacêutico devido as circunstâncias da pandemia. Abaixo no Quadro 1 identifica-se e descreve os procedimentos e alterações. Observa-se no Quadro 1 a descrição das principais mudanças ocorridas no período de Pandemia do vírus SARS-CoV-2 no ano de 2020. 
Quadro 1: Principais mudanças ocorridas no período de Pandemia de SARS-CoV-2, 2020.

\begin{tabular}{|c|c|}
\hline PARÂMETRO & MUDANÇAS \\
\hline VALIDADE DE RECEITUÁRIO & $\begin{array}{l}\text { Receitas médicas passam a ter a ter validade de } 365 \text { dias, inclusive retroativa, e } \\
\text { os pacientes podem comprar medicamentos para até } 90 \text { dias de tratamento. }\end{array}$ \\
\hline $\begin{array}{l}\text { MEDICAMENTOS } \\
\text { CONTROLADOS }\end{array}$ & $\begin{array}{l}\text { Os pacientes podem adquirir até seis meses de tratamento para controlados. } \\
\text { Porém medicamentos como a cloroquina, hidroxicloroquina e nitazoxanida } \\
\text { passaram a ter controle especial, a fim de evitar a compra indiscriminada por } \\
\text { conta da possível eficácia contra a Covid-19. }\end{array}$ \\
\hline $\begin{array}{l}\text { PRESCRIÇÃO ELETRÔNICA E } \\
\text { TELEMEDICINA }\end{array}$ & $\begin{array}{l}\text { A farmácia pode aceitar uma receita digital para dispensação de controlados } \\
\text { desde que com assinatura eletrônica certificada. }\end{array}$ \\
\hline $\begin{array}{l}\text { DISPENSAÇÃO NAS } \\
\text { FARMÁCIAS }\end{array}$ & Reorganização dos fluxos de atendimento. \\
\hline VACINAÇÃO & $\begin{array}{l}\text { Não houve mudança, porém a Anvisa abriu a possibilidade de farmácias sem } \\
\text { licença de vacinação poderem aplicar vacinas, desde que em parceria com poder } \\
\text { público e com ciência da VISA local, por meio das orientações da NOTA } \\
\text { TÉCNICA No 46/2020/SEI/GRECS/GGTES/DIRE1/ANVISA. }\end{array}$ \\
\hline TESTES RÁPIDOS & $\begin{array}{l}\text { A Anvisa aprovou, no dia } 28 \text { de abril, a aplicação de testes rápidos para a } \\
\text { detecção de Covid-19 em farmácias. A medida tem caráter temporário e } \\
\text { excepcional e visa ampliar a oferta e a rede de testagem. }\end{array}$ \\
\hline
\end{tabular}

Fonte: Autores.

\subsection{Mudanças na legislação farmacêutica durante a pandemia}

A portaria de consolidação $n^{\circ} 5$, de 28 de setembro de 2017, tem disposto no artigo 23 do Anexo LXXVII, que para o Programa Farmácia Popular Brasileiro (PFPB), as prescrições, laudos ou atestados médicos tem validade de 180 dias, a partir de sua emissão, exceto para os contraceptivos, cuja validade é de 365 (trezentos e sessenta e cinco) dias (Brasil, 2017).

No entanto a nota técnica 134 / 2020 CPFP / CGAFB / DAF / SCTIE / MS 0014039152 foi enviada através do ofício 473/2020 / CPFP / CGAFB / DAF / SCTIE / MS 0014039152, com o objetivo de tomar medidas de proteção contra o coronavírus. Portanto, a Coordenação do Programa Farmácia Popular - CPFP decidiu reformular o disposto na portaria de consolidação $\mathrm{n}^{\circ}$ 5, de 28 de setembro de 2017 em caráter excepcional e temporário, na resolução para que haja a comercialização e distribuição de medicamentos e / ou produtos afins no âmbito do PFPB, essas prescrições, laudos ou atestados médicos passaram a ser válidos por 365 dias da data de emissão (Brasil, 2020b).

Em consequência, amplia-se a quantidade dos itens a serem dispensados, observando-se a apresentação dos medicamentos, autorizar o uso de instrumento particular de procuração simples, sem a necessidade do reconhecimento de firma em cartório exigido pelo inciso III do artigo 25 do Anexo LXXVII da Portaria de Consolidação $n^{\circ}$ 5/2017, com poderes para aquisição, flexibilizando o disposto no artigo 23 do Anexo LXXVII da Portaria de Consolidação nº 5 , de 28 de setembro de 2017 (Brasil, 2020a).

Além disso foi criada também a Resolução da Diretoria Colegiada no 357, de 24 de março de 2020, esta estabelece, temporariamente, a extensão das quantidades máximas de medicamentos sujeitos a controle especial permitidas em Notificações de Receita e Receitas de Controle Especial, as quais estão previstas na Portaria SVS/MS n 344 , de 12 de maio de 1998 e nas Resoluções de Diretoria Colegiada n ${ }^{\circ} 58$, de 5 de setembro de 2007, nº 11, de 22 de março de 2011, e $n^{\circ} 191$, de 11 de dezembro de 2017, medicações observadas no Quadro 2, e permite, temporariamente, a entrega remota definida por programa público específico e a entrega em domicílio de medicamentos sujeitos a controle especial, em virtude da Emergência de Saúde Pública relacionada ao novo Coronavírus (Brasil, 2020a).

Ao verificar as receitas antes das vendas, a entrega remota de medicamentos controlados pode ter certas restrições. $\mathrm{O}$ período de validade da receita permanece inalterado. Aceita-se prescrições médicas digitais de medicamentos controlados e antibacterianos, desde que tenham assinatura eletrônica, mas não podem ser usados para notificações de prescrição (azul / 
amarelo) (Ferreira, 2020; Brasil, 2020c)

As receitas de controle especial eletrônico que passaram a ser aceitas referem-se aos medicamentos em que possuem nas fórmulas substâncias contidas nas listas C1 e C5 e os apêndices das listas A1, A2 e B1 da Secretaria de Vigilância Sanitária / Portaria do Ministério da Saúde no 344/1998. Assinaturas eletrônicas e prescrições digitais não são aplicáveis a outras prescrições eletrônicas de medicamentos controlados, como cupons de notificação de prescrição A (NRA), notificações de prescrição especial para talidomida, prescrições B e B2 de prescrição e sistemas de notificação de prescrição especial usando retinoides (Clinicarx, 2020; Brasil, 2020d).

De acordo com a lista a que pertence o medicamento, para pacientes que utilizam receitas do tipo amarela ou azul, podem receber a medicação para um período equivalente de até seis meses de tratamento. As vendas controladas por comércio eletrônico ainda são proibidas. Medicamentos como cloroquina, hidroxicloroquina e nitazoxanida passaram a ser especialmente controlados para evitar compras arbitrárias devido à sua possível eficácia contra Covid-19 (Ferreira, 2020). Nota-se no Quadro 2 abaixo as principais alterações na logística para realização de uma boa distribuição.

Quadro 2: Alteração RDC 344, de maio de 1998 - Anexo 1 da RDC nº 357, de março de 2020.

\begin{tabular}{|c|c|c|}
\hline $\begin{array}{l}\text { Tipo de } \\
\text { receituário }\end{array}$ & $\begin{array}{l}\text { Quantidades máximas por prescrição } \\
\text { Como era, antes das alterações }\end{array}$ & $\begin{array}{l}\text { Quantidades máximas por prescrição } \\
\text { Após alterações pela RDC } 357\end{array}$ \\
\hline $\begin{array}{l}\text { Notificação de } \\
\text { Receita A (NRA) }\end{array}$ & $\begin{array}{l}5 \text { unidades (sendo ampolas) ou } \\
\text { Quantidade para, no máximo, } 30 \text { dias de } \\
\text { tratamento (no caso das demais formas } \\
\text { farmacêuticas) }\end{array}$ & $\begin{array}{l}18 \text { unidades (sendo ampolas) ou } \\
\text { Quantidade para, no máximo, } 3 \text { meses de } \\
\text { tratamento (no caso das demais formas } \\
\text { farmacêuticas) }\end{array}$ \\
\hline $\begin{array}{l}\text { Notificação de } \\
\text { Receita B (NRB) }\end{array}$ & $\begin{array}{l}5 \text { unidades (no caso de ampolas) ou } \\
\text { Quantidade para, no máximo, } 60 \text { dias de } \\
\text { tratamento (no caso das demais formas } \\
\text { farmacêuticas) }\end{array}$ & $\begin{array}{l}18 \text { unidades (no caso de ampolas) ou } \\
\text { Quantidade para, no máximo, } 6 \text { meses de } \\
\text { tratamento (no caso das demais formas } \\
\text { farmacêuticas) }\end{array}$ \\
\hline $\begin{array}{l}\text { Notificação de } \\
\text { Receita B2 } \\
\text { (NRB2) }\end{array}$ & $\begin{array}{l}\text { Quantidade para, no máximo, } 30 \text { dias de } \\
\text { tratamento } \\
\text { * Exceto medicamento à base de sibutramina, } \\
\text { que poderá conter quantidade para, no } \\
\text { máximo, } 60 \text { dias de tratamento. }\end{array}$ & $\begin{array}{l}\text { Quantidade para, no máximo, } 3 \text { meses de } \\
\text { tratamento } \\
* \text { Exceto para medicamento à base de sibutramina, } \\
\text { que poderá conter quantidade para, no máximo, } 6 \\
\text { meses de tratamento. }\end{array}$ \\
\hline $\begin{array}{l}\text { Notificação de } \\
\text { Receita Especial } \\
\text { para Retinoides de } \\
\text { Uso Sistêmico } \\
\text { NRR) }\end{array}$ & $\begin{array}{l}5 \text { unidades (no caso de ampolas) ou } \\
\text { Quantidade de medicamento para, no } \\
\text { máximo, } 30 \text { dias de tratamento (no caso das } \\
\text { demais formas farmacêuticas) }\end{array}$ & $\begin{array}{l}18 \text { unidades (no caso de ampolas) ou } \\
\text { Quantidade de medicamento para, no máximo, } 3 \\
\text { meses de tratamento (no caso das demais formas } \\
\text { farmacêuticas) }\end{array}$ \\
\hline $\begin{array}{l}\text { Notificação de } \\
\text { Receita Especial } \\
\text { para Talidomida } \\
\text { (NRT) }\end{array}$ & $\begin{array}{l}\text { Quantidade de medicamento correspondente } \\
\text { a, no máximo, } 30 \text { dias de tratamento. }\end{array}$ & $\begin{array}{l}\text { Quantidade de medicamento correspondente a, no } \\
\text { máximo, } 3 \text { (três) meses de tratamento. } \\
\text { - Para mulheres em idade fértil: quantidade de } \\
\text { medicamento para, no máximo } 2 \text { meses de } \\
\text { tratamento }\end{array}$ \\
\hline $\begin{array}{l}\text { Notificação de } \\
\text { Receita da Lista } \\
\text { C3 - } \\
\text { Lenalidomida } \\
\text { (NRC3) }\end{array}$ & $\begin{array}{l}\text { Quantidade para } 1 \text { ciclo de tratamento, não } \\
\text { podendo ultrapassar o suficiente para } 30 \text { dias } \\
\text { de tratamento. }\end{array}$ & $\begin{array}{l}\text { Quantidade para } 3 \text { ciclos de tratamento, não } \\
\text { podendo ultrapassar o suficiente para } 3 \text { meses de } \\
\text { tratamento. } \\
\text { - Para mulheres com potencial de engravidar: } 2 \\
\text { ciclos de tratamento, não podendo ultrapassar o } \\
\text { suficiente para } 2 \text { meses de tratamento. }\end{array}$ \\
\hline $\begin{array}{l}\text { Receita de } \\
\text { Controle Especial } \\
\text { (RCE) }\end{array}$ & $\begin{array}{l}5 \text { unidades (no caso de ampolas) ou } \\
\text { Quantidade de medicamento para, no } \\
\text { máximo, } 60 \text { dias de tratamento (no caso das } \\
\text { demais formas farmacêuticas). } \\
\text { - Para antiparkinsonianos e } \\
\text { anticonvulsivantes, a quantidade ficará } \\
\text { limitada a até } 6 \text { meses de tratamento. }\end{array}$ & $\begin{array}{l}18 \text { unidades (no caso de ampolas) ou } \\
\text { Quantidade de medicamento para, no máximo, } 6 \\
\text { meses de tratamento (no caso das demais formas } \\
\text { farmacêuticas). } \\
\text { - Para antiparkinsonianos e anticonvulsivantes, a } \\
\text { quantidade ficará limitada a até } 6 \text { meses de } \\
\text { tratamento. }\end{array}$ \\
\hline
\end{tabular}

Fonte: Adaptado de Brasil (2020a). 
Desde que tenha uma assinatura eletrônica certificada, a farmácia pode aceitar prescrições digitais distribuídas pela empresa controlada. Esta é uma das mudanças regulatórias mais importantes até hoje. Uma receita digital é um documento gerado e mantido digitalmente com uma assinatura eletrônica válida e reconhecida pela Infraestrutura de Chaves Públicas Brasileira - ICP Brasil (Clinicarx, 2020; Brasil, 2020).

Antes de distribuir, a farmácia deve usar um verificador na Internet para verificar a autenticidade da receita digital recebida pelo paciente. A autenticidade da receita digital pode ser verificada diretamente no site na plataforma de emissão de receitas digitais (utilizada por médicos), ou a prescrição digital pode ser verificada diretamente no site do ITI com a chave identificada pela ICP Brasil (Clinicarx, 2020).

Em relação à consulta remota, os médicos podem emitir prescrições digitais. Devemos lembrar que a consulta médica presencial também pode gerar receitas digitais. Portanto, a telemedicina depende da prescrição eletrônica para ter efeito, mas a prescrição eletrônica não depende da telemedicina. Outros profissionais de saúde, como psicólogos, também prestam atendimento remoto (Clinicarx, 2020).

As informações das prescrições eletrônicas podem ser facilmente acessadas e ter rastreabilidade, podem estabelecer contato direto com o prescritor, minimizar erros de ortografia e reduzir a disseminação de receitas erradas. Pode ser usado uma assinatura digital para verificar o documento ou pode imprimir e assinar o documento manualmente (CFF, 2020). Desde que respeitada a norma da Infraestrutura de Chaves Públicas (ICP-Brasil), a Agência Nacional de Vigilância Sanitária (Anvisa) apoia o uso da assinatura digital nas prescrições médicas. A própria Anvisa reconhece que é possível assinar digitalmente medicamentos prescritos, que contêm as substâncias das Listas C1 a C5 e os anexos das Listas A1, A2 e B1 do Regulamento SVS / MS 344/98 e das prescrições de antimicrobianos.

Em comparação com os modelos dos Estados Unidos e da Europa, a tecnologia nessa área é retrógrada, principalmente na prescrição de medicamentos, que já dura mais de duas décadas. Nos Estados Unidos, melhorias nas plataformas de sistemas de prescrição (como prescrições eletrônicas) criadas há mais de 20 anos podem economizar US \$ 52 bilhões (mais de 251 bilhões de reais) a cada ano e tornar mais eficaz a rastreabilidade e controle da circulação de medicamentos pelo governo (Leonardi, 2020).

É importante ressaltar que entre os serviços técnicos que as farmácias podem prestar, para 75\% dos adultos brasileiros, o uso da receita eletrônica é considerado algo bem promissor, o que pode evitar problemas relacionados ao modelo atual de prescrição em papel. Esses dados são revelados pelo estudo ICTQ - Drug Market Research and Graduate School (2018), intitulado Hábitos relacionados à automedicação e práticas relacionadas a serviços e consumo de drogas em farmácia. Observe a Figura 1, no qual demonstra as principais normatizações quanto a logística de medicamentos e prescrições elaboradas durante a pandemia. 
Figura 2: Linha do tempo das legislações criadas no período da pandemia.

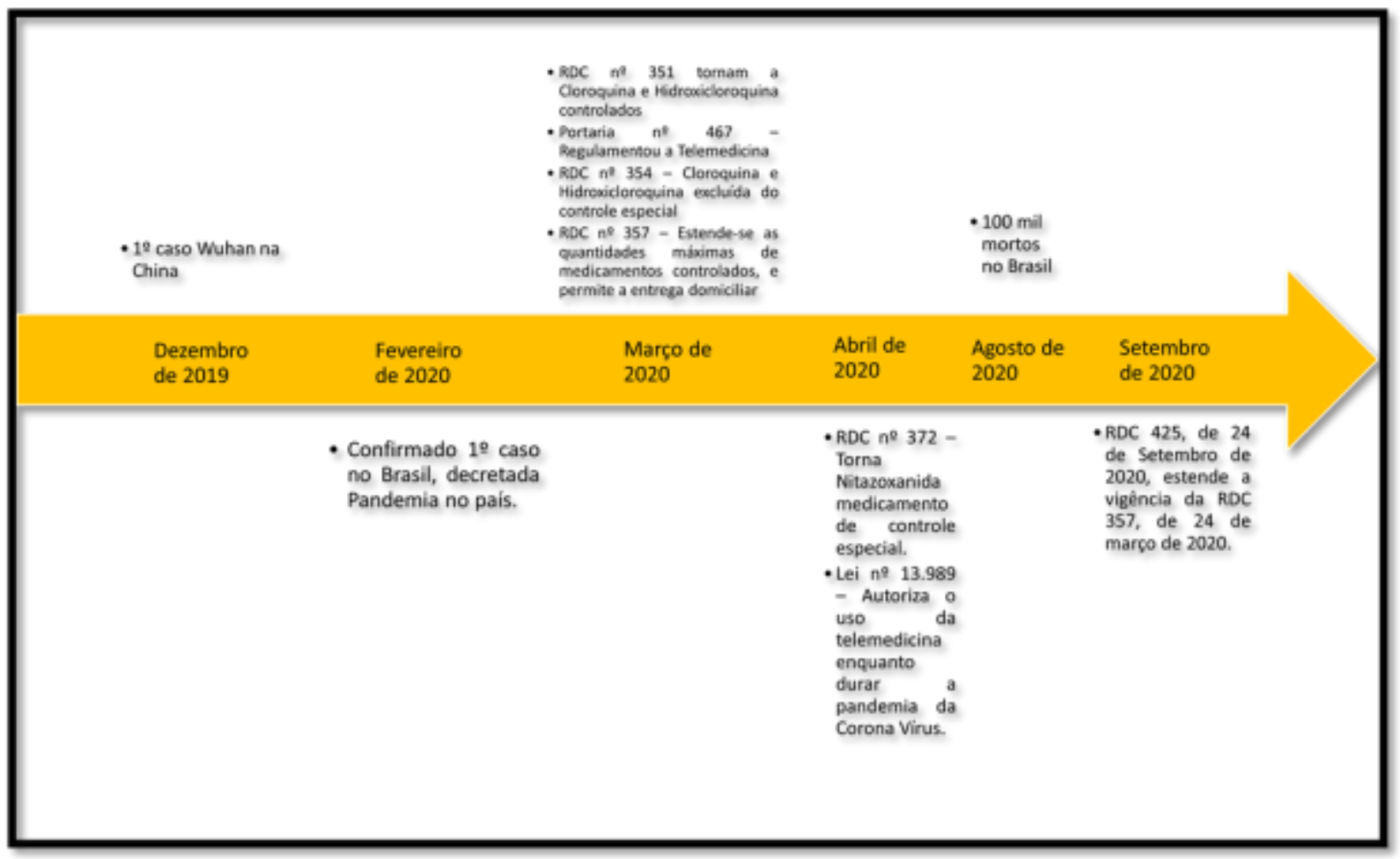

Fonte: Autores.

No Quadro 3 evidenciou-se um comparativo da legislação vigente antes da pandemia e durante o período da pandemia.

Quadro 3: Legislação vigente antes da pandemia e legislação vigente durante o período de pandemia.

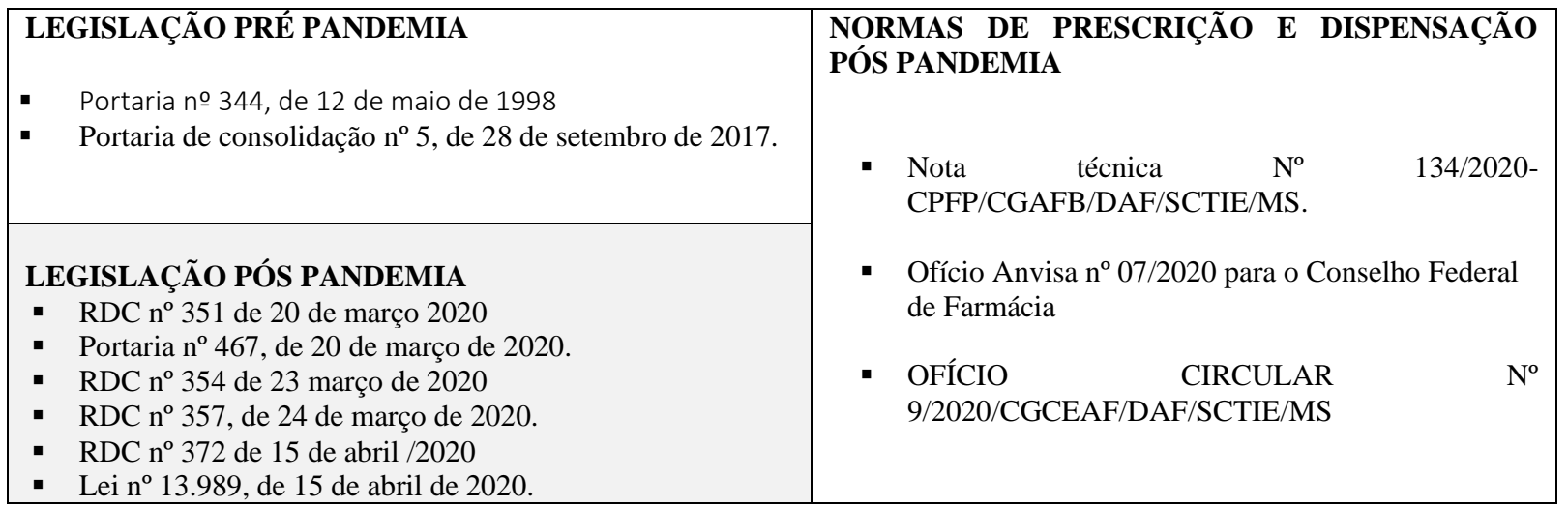

Fonte: Autores (2020).

\subsection{Atuação do farmacêutico diante da pandemia de Coronavírus}

O escopo clínico da infecção pelo novo coronavírus é amplo. De um simples resfriado a pneumonia e outras consequências graves. O quadro clínico inicial é uma síndrome semelhante à gripe, que pode evoluir para um aumento da temperatura corporal que dura de 3 a 4 dias. A taxa de mortalidade de pacientes hospitalizados varia entre $11 \%$ a $15 \%$, principalmente entre os idosos, portadores de hipertensão, diabetes, doença coronariana e coagulopatia. A intensidade e a frequência dos sintomas ajudam a determinar os cuidados a serem prestados. $\mathrm{Na}$ identificação de pacientes com sintomas, o 
atendimento clínico deve ser realizado na "área isolada da farmácia", de forma a proporcionar privacidade e proteção aos demais usuários e profissionais que atuam na instituição (Clinicarx, 2020).

Diante disso, independentemente dos sinais, todos os pacientes precisam ser orientados quanto às medidas de etiqueta respiratória e de higiene, bem como todos os resíduos potencialmente contaminados por usuários durante o atendimento devem ser descartados. Os farmacêuticos podem distribuir materiais educacionais ou vídeos aos pacientes, produzidos por fontes confiáveis como Ministério da Saúde, Conselhos Federal e Regional de Farmácia, etc. (CFF, 2020).

No sistema público municipal, a farmácia deve designar um farmacêutico para ser responsável pela tarefa de adquirir, armazenar e distribuir os medicamentos principais e ajustar seu inventário de acordo com o perfil epidemiológico da comunidade atendida e as mudanças nas necessidades de tratamento medicamentoso para garantir que o medicamento seja obtido em quantidade suficiente para uma prática clínica adequada (CRFSP, 2020).

Como membros da rede de saúde, farmacêuticos e farmácias devem auxiliar os indivíduos no registro de farmácias comunitárias públicas e privadas, cooperar com a identificação de casos e monitorar de perto a evolução clínica dos casos confirmados. Para pacientes com manifestações leves, o isolamento domiciliar e o tratamento ambulatorial são recomendados quando necessário (Ferreira, 2020).

Além das atividades acima mencionadas, podem encaminhar o cliente para os serviços de urgência e emergência ou a atenção primária à saúde (UBS, consultório médico); estipular quarentena e medidas de contenção dentro de seu escopo de ação; monitorar o isolamento de pacientes em casa, bem como de pacientes suspeitos com sintomas leves e a evolução do paciente confirmado. Portanto, seu desempenho é projetado para ajudar a otimizar funções de serviço mais complexas, reduzir a carga sobre o resto do sistema e minimizar situações em que grupos altamente poluentes podem contribuir para a infecção (CRFSP, 2020).

No que diz a respeito ao plano de gerenciamento de resíduos da farmácia deve ser adequado e aplicado a todos os funcionários sob a supervisão do farmacêutico e do gerente responsável. Eliminação de todos os poluentes em testes rápidos, consultas clínicas, EPI's pessoais etc. O farmacêutico deve seguir, no mínimo, as seguintes orientações gerais: utilizar recipiente de material lavável para a dispensação de resíduos com alto nível de contaminação, para assim evitar perfuração, rompimento, vazamento e despejo, e sua tampa deve ser dotada de tampa com sistema de abertura arredondada que não necessite de contato manual, além da utilização de métodos ou imagens ilustrativas que indiquem alto nível de contaminação (CFF, 2020).

Quase 20\% de todos os casos de Covid-19 requerem hospitalização para tratamento sub-intensivo ou intensivo, o que impõe uma carga adicional aos laboratórios clínicos, que são forçados a produzir muitos resultados críticos (de emergência) no menor tempo possível. Neste caso, a medicina laboratorial mostrou mais uma vez a sua adaptabilidade inerente e bem conhecida, de acordo com a qual os profissionais de laboratório continuam a fornecer resultados de testes importantes para diagnosticar, prever e gerir pacientes com Covid-19 (Lippi; Plebani, 2020).

A pandemia COVID-19 representa um grande desafio para os laboratórios de análises clínicas (LACs) em todas as etapas de sua produção. Dentre eles, na fase de pré-análise, destaca-se pelo fato de que embora haja um conjunto completo de procedimentos de higienização das mãos, móveis, utensílios e procedimentos de desinfecção de superfícies, esses procedimentos requerem ajustes especiais às características da doença, como sua alta transmissão. Ajustar rapidamente a área de serviço e coletar materiais biológicos para garantir a distância mínima entre funcionários, entre funcionários e clientes, e entre clientes para reduzir a possibilidade de gotículas e gotículas espalharem Sars-CoV-2 (Terrão, 2020).

Pela grande demanda por amostras de teste RT-PCR, os gerentes técnicos da LAC são obrigados a se adequar aos procedimentos operacionais padrão (POP), especialmente a atribuição e dispensa de profissionais responsáveis pela coleta e até mesmo treinamento de novos funcionários. A definição do protocolo de validação permite entender a sensibilidade, 
especificidade e reprodutibilidade desses reagentes mobilizados pelas sociedades científicas no campo da análise clínica e pelo gerente técnico do LAC para garantir a seleção e uso da qualidade analítica exigida pelos kits que atendem aos seguintes padrões. Garantindo assim resultados confiáveis e seguros. Os laboratórios precisam adaptar seu plano de gerenciamento de resíduos médicos à realidade da COVID-19, aumentando a quantidade de resíduos contaminados específicos. Por fim, todo o departamento de análises clínicas precisa se perguntar quais lições precisamos aprender com a situação atual e como nos preparar o menos para possíveis situações futuras (Terrão, 2020).

\section{Considerações Finais}

Com a pandemia da coronavírus houve muitas modificações nas legislações com propósito de reduzir o contágio viral através da diminuição do contato social e em relação ao tratamento medicamentoso, alterando as receitas médicas e atualizando as listas de medicamentos de controle especial. As principais mudanças que ocorreram na legislação foram: o aumento do prazo de validade das prescrições e modificações na quantidade dispensada de medicamentos, a restrição aumentada para algumas medicações, como por exemplo a cloroquina em que a procura aumentou devido a disseminação de informações sobre seu uso para o tratamento da Covid-19, além das mudanças em relação ao atendimento por meio virtual e aceitação de prescrições digitais com assinatura eletrônica.

Desse modo o estudo sistemático de períodos e das legislações permite que o farmacêutico conheça as mudanças ocorridas nas legislações, sendo o profissional fundamental no controle da propagação do vírus e do cuidado aos pacientes portadores da doença bem como sua atuação em meio a pandemia possui implicações diretas no que se refere ao controle e dispensação de medicações, auxílio direto e indireto no cuidado aos pacientes sintomáticos, atuando no controle e organização das farmácias, contribuindo de forma imprescindível com a saúde pública.

Compreendemos que o presente trabalho poderá servir como ponto de partida para outras pesquisas e/ou estudos a serem desenvolvidos, favorecendo o desenvolvimento de ações educativas e de assistência que promovam o fortalecimento do papel do farmacêutico frente ao coronavírus. $\mathrm{O}$ estudo sistemático e periódico das legislações permite que o farmacêutico conheça as mudanças ocorridas na legislação farmacêutica, tenha autonomia para desempenhar seu papel com eficácia e qualidade e contribuía de forma mais qualificada para os novos desafios apresentados. A desconstrução e reconstrução do paradigma social e econômico que deverá vir à tona no contexto da pós-pandemia Covid-19 trará impactos no mundo do trabalho, podendo apontar caminhos para os profissionais de saúde.

\section{Referências}

Agência Brasilia. (2020). Liberação de medicamentos terá mudanças durante a pandemia. https://www.agenciabrasilia.df.gov.br/2020/04/01/liberacao-de medicamentos-tera-mudancas-durante-a-pandemia.

Araujo, T. S. et al (2020). Comitê de Enfermagem para Enfrentamento da COVID-19 na Bahia. Rev. Bras. Enferm., 73(supl. 2), e20200469.

Brasil. Resolução RDC No 357, DE 24 DE Março (2020a). Esta Resolução estabelece, temporariamente, a extensão das quantidades máximas de medicamentos sujeitos a controle especial permitidas em Notificações de Receita e Receitas de Controle Especial, as quais estão previstas na Portaria SVS/MS $\mathrm{n}^{\circ}$ 344, de 12 de maio de 1998 e nas Resoluções de Diretoria Colegiada - RDCs n ${ }^{\circ} 58$, de 5 de setembro de 2007, $\mathrm{n}^{\circ} 11$, de 22 de março de 2011, e ${ }^{\circ}$ 191, de 11 de dezembro de 2017. Brasília. https://www.pucsp.br/sites/default/files/Guia\%20para\%20elabora\%C3\%A7\%C3\%A3o\%20de\%20refer $\%$ C3\%AAncias $\% 20 \mathrm{de} \% 20$ acordo\%20com\%20a\%20norma\%20da\%20ABNT\%20dez\%202018.pdf.

Brasil. Portaria N ${ }^{\circ}$ 467, DE 20 DE Março (2020b). Dispõe, em caráter excepcional e temporário, sobre as ações de Telemedicina, com o objetivo de regulamentar e operacionalizar as medidas de enfrentamento da emergência de saúde pública de importância internacional previstas no art. $3^{\circ}$ da Lei $\mathrm{n}^{\circ} 13.979$, de 6 de fevereiro de 2020, decorrente da epidemia de COVID-19. Brasília. https://www.in.gov.br/en/web/dou/-/portaria-n-467-de-20-de-marcode-2020249312996

Brasil. Lei N ${ }^{\circ}$ 13.989, DE 15 DE Abril (2020c). Dispõe sobre o uso da telemedicina durante a crise causada pelo Coronavírus (SARS-CoV-2). Brasília. https://www.in.gov.br/en/web/dou/-/lei-n-13.989-de-15-de-abril-de-2020-252726328.

Brasil. Nota Técnica No 134/2020-CPFP/CGAFB/DAF/SCTIE/MS (2020d). Trata-se de alteração, em caráter excepcional e temporária, no âmbito do Programa Farmácia Popular do Brasil (PFPB) - "Aqui Tem Farmácia Popular", no que diz respeito às regras previstas no item 8 do "Manual de Orientações às 
Farmácias e Drogarias Credenciadas no Aqui Tem Farmácia Popular" (referenciado no artigo 24 da Portaria de Consolidação nº 5 de 28 de setembro de 2017). Brasília. https://www.cff.org.br/userfiles/file/03.pdf.

Brasil. Portaria De Consolidação Nº 5, de 28 De Setembro (2017). Consolidação das normas sobre as ações e os serviços de saúde do Sistema Único de Saúde. Brasília.https://portalarquivos2.saude.gov.br/images/pdf/2018/marco/29/PRC-5-Portaria-de-Consolida----o-n---5--de-28-de-setembro-de-2017.pdf.

Brasil. Portaria $\mathrm{n}^{\circ}$ 344, de 12 de maio (1998). Aprova o Regulamento Técnico sobre substâncias e medicamentos sujeitos a controle especial. Brasília. https://bvsms.saude.gov.br/bvs/saudelegis/svs/1998/prt0344_12_05_1998_rep.html.

Brasil. Resolução - RDC No 354, de 23 De Março (2020d). Altera a Resolução de Diretoria Colegiada - RDC no 351, de 20 de março de 2020. Brasília. https://www.in.gov.br/en/web/dou/-/resolucao-rdc-n-354-de-23-de-marco-de-2020-249317430.

Brasil. Resolução - RDC No 357, de 24 De Março (2020e). Estende, temporariamente, as quantidades máximas de medicamentos sujeitos a controle especial permitidas em Notificações de Receita e Receitas de Controle Especial e permite, temporariamente, a entrega remota definida por programa público específico e a entrega em domicílio de medicamentos sujeitos a controle especial, em virtude da Emergência de Saúde Pública de Importância Internacional (ESPII) relacionada ao novo Coronavírus (SARS-CoV-2). Brasília. https://www.in.gov.br/en/web/dou/-/resolucao-rdc-n-357-de-24-de-marco-de-2020-249501721.

Brasil. Resolução - RDC No 372, de 15 de Abril (2020). Dispõe sobre a atualização do Anexo I (Listas de Substâncias Entorpecentes, Psicotrópicas, Precursoras e Outras sob Controle Especial) da Portaria SVS/MS $\mathrm{n}^{\circ} 344$, de 12 de maio de 1998, e dá outras providências. Brasília. https://www.in.gov.br/en/web/dou/-/resolucao-rdc-n-372-de-15-de-abril-de-2020-252726528.

Clinicarx (2020). Mudanças regulatórias durante a pandemia da Covid-19. https://www.assistenciafarmaceutica.far.br/mudancas-regulatorias-durante-apandemia-da-covid-19/.

CRFSP- Conselho Regional de Farmácia São Paulo (2020). Farmacêuticos contra o novo Coronavírus. http://www.crfsp.org.br/noticias/11172-covid-192.html.

CFF-Conselho Federal de Farmácia (2020). Coronavírus: atuação do farmacêutico frente à pandemia da doença causada pelo Coronavírus. https://www.cff.org.br/userfiles/Coronav\%C3\%ADrus\%20orienta\%C3\%A7\%C3\%B5es\%20a\%20Farm\%C3\%A1cias\%20da\%20APS\%20no\%20SUS\%20(1). pdf.

Ferreira M. M. (2020). Como será a profissão farmacêutica depois que essa pandemia acabar? https://www.ictq.com.br/opiniao/1332-como-sera-a-profissaofarmaceutica-depois-que-essa-pandemia-acabar.

Ferenhof, H. A. \& Fernandes, R. F. (2016). Desmistificando a revisão de literatura como base para redação científica: método ssf. Revista ACB, 21 (n.3), 550563.

Javelot, H. et al (2020). Informations relatives aux psychotropes et à leurs adaptations éventuelles pour les patients souffrant de troubles psychiques en France pendant l'épidémie à SARS-CoV-2. Encephale.46 (n.3S), 14-34.

Karuppiah, S. L. (2020). Ganotherapy and Holistic Human System Is the Pathway of Holistic Health for Immediate Relief for COVID19. Open Journal of Preventive Medicine.10, 45-61. 10.4236/ojpm.2020.103003.

Leonardi, E. (2020). Nova lei obriga prescrição médica eletrônica no Brasil. https://www.ictq.com.br/varejo-farmaceutico/1289-nova-lei-obriga-prescricaomedica-eletronica-no-brasil.

Lippi, G. \& Plebani, M. (2020) Resiliência dos laboratórios clínicos durante a pandemia de coronavírus 2019 (Covid-19). J. Bras. Patol. Med. Lab. 56, e3202020.

Mahmood, G. (2020). COVID 19 Diagnostic Tests: A Study of 12,270 Patients to Determine Which Test Offers the Most Beneficial Results. Surgical Science.11, 82-88. 10.4236/ss.2020.114011.

Dourado, M. L. (2020). O Profissional Farmacêutico, a ética e a COVID-19: fiscalização e ética. FISCALIZAÇÃO E ÉTICA. https://www.crfma.org.br/oprofissional-farmaceutico-a-etica-e-a-covid-19/.

Silva, A. C. O. et al. (2020). Máscara de tecido como proteção respiratória em período de pandemia da covid-19: lacunas de evidências. Rev. Bras. Enferm., Brasília.73 (supl. 2), e20200239.

Morales, P. S. (2020). O que é, como solicitar e qual é a única técnica laboratorial validada, até o momento, para coronavírus? Graduação em Medicina pela Universidade Gama Filho. https://pebmed.com.br/o-que-e-como-solicitar-e-qual-e-a-unica-tecnica-laboratorial-validada-ate-o-momento-para-coronavirus/.

Terrão, J. L. J. (2020). Papel do laboratório clínico na pandemia de Coronavírus. RBAC. 10.21877/2448-3877.20200010. http://www.rbac.org.br/artigos/papeldo-laboratorio-clinico-na-pandemia-de-coronavirus. 